\title{
A EXPLORAÇÃO DO TRABALHO NO PÓS-FORDISMO: a realidade do call center ${ }^{12}$
}

Paolo Caputo ${ }^{3}$

Giuseppina de Grazia ${ }^{4}$

Resumo: Este artigo analisa a morfologia e as características do trabalho no call center e, mais genericamente, o chamado trabalho imaterial. O retorno a Marx, à especificidade da natureza humana e ao conceito de força de trabalho são as "armas" teóricas que abrem caminho para uma releitura crítica das formas de exploração no capitalismo contemporâneo. Perscrutando quanto há de mais vivo no pensamento de Marx, busca-se lançar luz sobre as condições de alienação sistemática do trabalho cognitivo na atualidade.

Palavras chave: força de trabalho, trabalho cognitivo, call center.

Abstract: The paper examines the nature, characteristics, and features of callcenter work and, more generally, of the so-called cognitive work. The return to Marx, to the specific nature of the human nature (species-essence) and the concept of labour power are the theoretical "weapons" to carry out a critical analysis of the forms of exploitation in contemporary capitalism. This paper aims to highlight the relevance of Marx's theory to shed light on the conditions of systematic alienation of cognitive work.

Keywords: labour power, cognitive work, call center.

\section{A especificidade do ser humano e o conceito "força de trabalho"}

Antes de entrarmos na análise das especificidades que caracterizam a subsunção do trabalho linguístico e cognitivo-relacional dos operadores de call center (e, mais amplamente, de grande parte do chamado trabalho intelectual na fase atual do desenvolvimento do capital), faz-se necessário explicitar alguns conceitos chave que orientam nossa análise. Em particular, é preciso definir preliminarmente o que entendemos pelo conceito de força produtiva (tanto física como mental) e, para fazê-lo, partiremos da definição marxiana de força de trabalho.

\footnotetext{
${ }_{1}^{1}$ DOI: https://doi.org/10.22409/tn.15i27.p9636

${ }^{2}$ In CAPUTO, Paolo (org.) Call Center. La morte delle parole - Sfruttamento, alienazione e conflito. Milano, Ed. The Writer, 2013.

${ }^{3}$ Professor da UNICAL (Universidade da Calabria, Itália), no Depto. de Ciências Políticas e Sociais.

${ }^{4}$ Tradução: Giuseppina De Grazia, doutora em Sociologia (USP), ex-professora da UFF no Depto.de Serviço Social.
} 
Para Marx, a força de trabalho (ou capacidade de trabalho) é constituída pelo conjunto de habilidades, atividades físicas e mentais presentes na corporalidade (na carne e no sangue do homem ${ }^{4}$ ), na personalidade viva de um homem e que ele transforma em ato, isto é, coloca em ação a cada vez que produz "coisas" úteis, valores de uso de qualquer espécie ${ }^{5}$. Substancialmente, o conceito de força de trabalho nos remete às intrínsecas capacidades, faculdades, potencialidades produtivas, intelectuais e linguístico-comunicativas, próprias da espécie humana ${ }^{6}$ e que, portanto, distinguem o animal humano daqueles não humanos.

Referindo-se à atividade humana, Marx afirma que a atividade livre e consciente é precisamente o que caracteriza o ser humano:

[...] A atividade vital consciente distingue o homem imediatamente da atividade vital animal. [...] É verdade que também o animal produz. Constrói para si um ninho, habitações, como a abelha, o castor, a formiga, etc. No entanto, produz apenas aquilo de que necessita imediatamente para si ou sua cria; produz em modo unilateral, enquanto o homem produz em modo universal; o animal produz apenas sob o domínio da carência física imediata, enquanto o homem produz mesmo livre da carência física, e só produz verdadeiramente quando se sente livre em relação a ela [...]. Precisamente por isso, na transformação do mundo objetivo é que o homem se confirma, em primeiro lugar e efetivamente, como ser genérico. Esta produção é a sua vida genérica operativa, como ser pertencente a uma 'espécie'. (MARX, 2004, p. 74-75).

Para a antropologia filosófica, tudo isso é determinado pelo fato de que o homem, diferentemente dos outros animais, é dotado apenas de pulsões indefinidas e imprecisas, faculdades genéricas (GHELEN, 1990), ao contrário dos instintos especializados dos animais, os quais, organizando um determinado modo de viver, articulando um específico modo de ser, garantem a sobrevivência das espécies animais. Graças ao seu específico aparato instintivo, os animais não agem: limitam-se a re-agir aos estímulos ambientais correlacionados aos seus instintos. Ao contrário, o animal humano, " [...] privado de uma sólida base

\footnotetext{
${ }^{4}$ MARX, 1977, p.33.

${ }^{5} \mathrm{O}$ trabalho é, portanto, a força de trabalho em ação.

${ }^{6}$ Como observa Vygotskij (1987), no animal humano, e somente nele, temos uma unidade de percepção, linguagem e ação. Em outras palavras, a linguagem e a atividade prática, a utilização de instrumentos e sinais, a cultura e a técnica constituem parte de uma mesma e complexa função psíquica.
} 
instintiva, é obrigado a agir para sobreviver, a construir-se um mundo para suprir a falta de um ambiente já pronto para ele." (GALIMBERTI, 2008, p.161).

Marx ainda sustenta que os homens, diferentemente dos animais, possuem uma história justamente porque, devido à sua constituição física e biológica, devem produzir a própria vida e devem fazê-lo de uma forma determinada:

\begin{abstract}
A primeira ação histórica é, portanto, a criação dos meios para suprir estas necessidades (a começar pelas carências físicas indispensáveis à pura e simples sobrevivência da vida humana) ou seja, a produção da própria vida material. E esta é precisamente uma ação histórica, condição fundamental de toda história [...]. Um segundo ponto é que a primeira necessidade satisfeita, a ação de satisfazê-la e o instrumento já descoberto para essa realização, levam a novas necessidades [...]. (CIMATTI, 2000, p.18-19).
\end{abstract}

A capacidade de antecipação, a ideação, o planejamento, a liberdade de movimento e de ação, em uma palavra: a história como sucessão de auto criações tem como raiz, em última instância, a constituição biológico-orgânica do ser humano, e no agir técnico sua forma de expressão. ${ }^{7}$ Nesse sentido, o ser humano, ao contrário dos outros animais, produzindo o próprio ambiente (cultura) $)^{8}$, tem uma história. Sublinhamos que, neste contexto, com o termo produção não nos referimos, obviamente, ao indivíduo singular, mas à produção social (à produção socialmente determinada pelos indivíduos) ${ }^{9}$ :

A produção por indivíduos isolados, fora da sociedade - fato raro que pode ocorrer muito bem quando um civilizado, que possui dinamicamente em si mesmo as forças da sociedade, se extravia acidentalmente num meio selvagem - é algo tão insensato como o desenvolvimento da linguagem na ausência dos indivíduos que vivem e falam juntos. (MARX, 1968, p.5).

Efetivamente, como evidenciado pela antropologia, o ser humano é literalmente um ser, um animal social e, enquanto tal, sua necessidade primária é

\footnotetext{
7 "(...) a qual nos diz que o homem é corpo/cérebro genericamente aberto ao mundo, potencialmente apto e exposto à relação com o outro". (PEZZANO, 2012, p.4).

${ }^{8}$ A cultura é, portanto, a "segunda natureza" do ser humano e "o mundo da cultura é o mundo humano" (GEHLEN, 1990, p. 64).

${ }^{9} \mathrm{Na}$ produção os homens não atuam só sobre a natureza mas também uns sobre os outros. Produzem apenas atuando conjuntamente de um modo determinado e trocando as suas atividades umas pelas outras. Para produzirem entram em determinadas ligações e relações uns com os outros, e só no seio destas ligações e relações sociais se efetua a sua ação sobre a natureza, se efetua a produção. (MARX 1977, p.47).
} 
interagir com outras pessoas. (DOUGLAS, 1994). A reciprocidade constitui o princípio fundamental para assegurar a própria sobrevivência ${ }^{10}$. Em síntese, tanto a atividade humana produtiva como a atividade mental não constituem processos solitários, solipsistas. São atividades sociais vivenciadas com os outros e feitas para serem comunicadas, partilhadas e desenvolvidas junto aos outros.

O ser humano produz o próprio ambiente, o próprio contexto vital, a própria existência (podemos impropriamente dizer que esta é a sua natureza), e só pode fazer tudo isso a partir da e na "natureza", do contexto vital no qual está inserido, "[...] que representa para ele o mundo externo sensível, a matéria sobre a qual e com a qual realiza seu trabalho, sobre a qual e com a qual seu trabalho se desenvolve, da qual e por meio da qual produz". (Pezzano, 2012).

O homem produz e reproduz as condições na base da própria existência através de um processo de objetivação, de explicitação, de exteriorização das próprias necessidades sob muitas formas, tanto materiais como simbólicas (técnica e linguagem, instrumentos e símbolos, produção e cultura). ${ }^{11}$

A linguagem permite ao nosso cérebro (que do ponto de vista anatômico e genético apresenta-se de forma muito similar ao de tantos outros animais) adquirir a capacidade - ao término de um processo de desenvolvimento que se inicia na infância - de dar vida a uma mente com desempenho completamente diferente do gênero que caracteriza os outros animais. Em resumo, a mente humana fundamenta-se num princípio diverso daquele que constitui a mente dos animais não humanos: o pensamento humano é um pensamento "verbal" enquanto o dos outros animais é um pensamento perceptivo ${ }^{12}$, e por essa razão, a principal característica do raciocínio humano provém da versatilidade e da criatividade:

\footnotetext{
${ }^{10}$ De resto, também a atividade mental humana, assim como a produção (a técnica) não é algo solitário, nem existe sem ajuda, mesmo quando ocorre "no interior da cabeça": "Somos a única espécie que absorve toda forma significativa de ensinamento. A vida mental é vivida com os outros, é feita para ser comunicada e se desenvolve com a ajuda de códigos culturais, tradições e semelhantes." (BRUNER, 2001, p.9).

${ }_{11}$ Referindo-se ao desenvolvimento humano e, em particular, ao papel desenvolvido pela utilização de instrumentos e símbolos no desenvolvimento da criança, também Vygotskij (1987, p.42) evidencia que a unidade dialética entre a inteligência prática (utilização de instrumentos) e o uso de sinais (a linguagem, em particular) constitui a própria essência do complexo comportamento humano.

${ }^{12} \mathrm{~A}$ diferença entre o animal humano e aquele não humano é, portanto, o fato de que o primeiro pensa em termos linguísticos, ou seja, literalmente pensa em palavras, enquanto o segundo somente pode pensar em termos perceptivos, isto é, a partir daquilo que vê, e não do que lhe é dito. Assim como também não poderia dizer internamente a si mesmo aquilo que vê. A diferença, portanto, está na forma diferente de utilização de suas linguagens naturais: para o primeiro, ela
} 
A característica principal da inteligência humana é a sua flexibilidade, o que pressupõe a possibilidade de assentar os processos cognitivos, inclusive aqueles existentes apenas na imaginação [...] sobre o potencial criativo das línguas humanas. Flexibilidade que, por sua vez, significa essencialmente capacidade de gerar hipóteses para depois submetê-las ao filtro seletivo da prova dos fatos. (CIMATTI, 2002, p.196).

É necessário salientar que o animal humano não possui mais imaginação que um chipanzé ou um cão porque é mais inteligente do que esses animais,

e sim porque - graças à sua mente organizada linguisticamente é capaz de superar os vínculos que a percepção impõe ao seu pensamento. $O$ que se pode fazer com um determinado objeto depende, além de sua potencialidade corpórea de base (um golfinho não poderá fazer muita coisa com uma chave de fenda, apesar de ser um mamífero muito inteligente), da capacidade mental de associação com outros objetos e situações. Mas esta capacidade não depende tanto do objeto em si (embora seja difícil utilizar uma serra elétrica para cortar uma verruga), nem da imaginação, quanto da possibilidade cognitiva de isolar o objeto em questão da rede vinculante de associações na qual habitualmente está inserido. Somente depois de tê-lo isolado e individualizado como entidade independente, é possível colocá-lo em relação com outros objetos e outros contextos perceptivos. Em nossa mente, e na de nosso ancestral hominídeo, o principal instrumento para realizar essa articulação e separação é dado pela linguagem. (CIMATTI, 2000, p.132-133).

No caso do animal não humano, entretanto, seus instintos especializados saturam o conjunto das possibilidades que um determinado organismo pode alcançar,

[...] instintos que, no caso dos animais não humanos, [...] restringem 0 espaço das possibilidades, porque vinculam estreitamente o animal, através do qual se manifestam, ao seu ambiente mais imediato. O instinto da linguagem, ao contrário, é o instinto do possível, da abertura, da fantasia, se assim se deseja. Um instinto que se desenvolve naquela infância prolongada que é a vida do ser humano como capacidade discursiva, como autoconsciência, como inesgotável abundância de possibilidades em relação à realidade. (CIMATTI, 2002, p.209).

serve não só para se comunicar mas também, e sobretudo, para pensar; para os não humanos, essencialmente para comunicar. (CIMATTI, 2000, P. 129). 
Vygotskij nos lembra que, no momento em que as crianças aprendem a utilizar de modo eficaz a função de programar sua linguagem, seu campo cognitivo muda radicalmente ${ }^{13}$ :

E ainda:

Ao contrário do macaco [...] que é 'escravo de seu próprio campo visual', as crianças adquirem uma independência no enfrentamento de tudo o que concretamente as circunda; elas cessam de agir no espaço imediato e evidente [...]. Uma visão do futuro torna-se parte integrante do seu modo de aproximar-se do que as rodeia. (VYGOTSKIJ, 1987, p.49).

[...] As crianças resolvem os problemas práticos com a ajuda seja da linguagem, seja dos olhos e mãos. Esta unidade de percepção, linguagem e ação, que ao final produz a interiorização do campo visível, constitui tema central para qualquer análise da origem de formas de comportamento unicamente humanas [...]. É decisivamente importante que a linguagem não só facilite a efetiva manipulação dos objetos à criança, mas também o controle sobre seu próprio comportamento. Portanto, com a ajuda da linguagem, a criança, ao contrário do macaco, adquire a capacidade de ser tanto o sujeito, como também o objeto de seu próprio comportamento. (Idem, p.45-46).

Em suma, para o ser humano, o produto cresce com o instrumento e, na sua gênese como no seu uso cotidiano, o pensamento sem a linguagem resulta ser tão inconcebível como seria o raciocínio matemático desenvolvido sem 0 suporte de um adequado simbolismo matemático. "Portanto, desenvolvimento da linguagem e desenvolvimento do pensamento correm paralelamente." (PETRACCHI, 1995, p.55).

Como observa Leroi-Gourhan - segundo o qual a linguagem constitui o instrumento de libertação em relação à experiência vivida, da mesma forma que o instrumento é o meio de libertação dos vínculos genéticos - existe uma estreita interdependência entre gesto e palavra, técnica e linguagem, objetivação instrumental e simbólica:

\footnotetext{
${ }^{13} \mathrm{O}$ comportamento mais importante na utilização de sinais por parte das crianças é de longe a linguagem humana. Através dela as crianças se libertam de muitas das coerções presentes em seu ambiente. Elas se preparam para as atividades futuras; planejam, ordenam e controlam seu comportamento como o das outras pessoas. A linguagem é também um excelente exemplo de utilização de sinais, a qual, uma vez interiorizada, torna-se parte intensa e profunda dos processos psíquicos superiores; a linguagem atua para organizar, unificar e integrar muitos aspectos heterogêneos do comportamento das crianças, como a percepção, a memória e a resolução de problemas. (VYGOTSKIJ, 1987, p.183-184).
} 
[...] o homem fabrica utensílios concretos e símbolos, e tanto uns como os outros nascem de um mesmo processo, ou melhor, recorrem, no cérebro, ao mesmo equipamento básico. Isto nos leva a pensar não apenas que a linguagem é tão típica do homem quanto os utensílios, mas também que ambos são a expressão da mesma faculdade do homem. (LEROI-GOURHAN, 1977, p.267).

O que foi tratado até aqui implica também em afirmar que a mente humana não poderia existir sem a cultura ${ }^{14}$, ou seja, sem um sistema simbólico compartilhado pelos membros de uma comunidade cultural através do qual a realidade pode ser representada:

[...] a cultura plasma a mente, nos fornece o conjunto dos utensílios mediante os quais construímos não só nosso mundo, mas também a concepção que temos de nós mesmos e de nossas capacidades. [...] O conhecimento e a comunicação, por sua própria natureza, são profundamente interdependentes, diria mesmo praticamente inseparáveis. De fato, mesmo que possa parecer que o indivíduo atue por conta própria na sua busca de significados, não pode fazê-lo, assim como ninguém conseguiria fazê-lo, sem o auxílio dos sistemas simbólicos da própria cultura. É a cultura que nos fornece os instrumentos para organizar e compreender 0 nosso mundo em formas comunicáveis. A característica que distingue a evolução humana está vinculada à particular evolução da mente, a qual se desenvolveu de modo tal a consentir aos seres humanos a utilização dos instrumentos da cultura. Sem estes instrumentos, simbólicos ou materiais, o homem não seria um "macaco mudo", mas só uma vazia abstração. (BRUNER, 2001, p.17).

Podemos concluir com Vygotskij (1987) que as qualidades únicas de nossa espécie estão baseadas sobre as dimensões sociais da vida humana, criadas historicamente e elaboradas culturalmente, dimensões que se fundam a partir da utilização de sinais e de instrumentos, ausentes na organização social dos animais não humanos. Sistemas de instrumentos e de sinais construídos pela sociedade ao longo do curso da história da humanidade e que se transformam junto com as diversas formas assumidas pela sociedade e o nível de seu desenvolvimento cultural. A utilização de instrumentos e sinais, a capacidade de manipulação e a linguagem entre os homens andam de mãos dadas e implicam algumas propriedades importantes em comum: ambas comportam a atividade mediata. Agnes Heller escreve que "no processo de objetivação do homem os

\footnotetext{
14 "Como gostam de dizer alguns antropólogos, a cultura é uma caixinha de apetrechos contendo as técnicas e procedimentos para compreender e administrar o mundo." (BRUNER, 2001, p.111).
} 
sentidos humanos são exteriorizados e é a relação humana objetivada, já presente, que desenvolve em cada ser humano, tanto quanto possível, os sentidos e as necessidades humanas. (HELLER, 1977, P.44). Ou ainda, como afirma Berthoud, a característica própria da condição humana de estar no mundo reside na progressiva separação de uma parte sempre maior de si mesmo que se exterioriza em objetos materiais e simbólicos ${ }^{15}$ :

Há, portanto, sempre - mesmo que seja possível perceber de forma aproximativa diversos graus de exteriorização - uma objetivação material e social na relação entre o homem e o mundo. O EU, no seu papel de ser social, expõe de alguma forma no exterior de si mesmo uma parte de seu interior. Dessa forma funções e saberes são exteriorizados. (BERTHOUD, 1994, p.55).

\section{A força de trabalho no pós-fordismo}

Do que foi analisado até aqui, a definição marxiana de força de trabalho de imediato e obrigatoriamente nos reconduz às características biológicas específicas do ser humano, do ser em potencial, as quais se expressam precisamente naquelas que são as potencialidades físicas e intelectuais próprias de nossa espécie. Força de trabalho significa faculdade de produzir, potência bruta, genérica e indeterminada:

Nela não está prescrito um ou outro tipo particular de atos laborativos, e sim atos de qualquer espécie: tanto a fabricação de uma porteira, quanto a colheita de peras; tanto a conversa de um telefonista das chat-lines, quanto a correção de textos[...]. Falando de força de trabalho, nos referimos explicitamente a todo tipo de faculdade: competência linguística, memória, capacidade de movimento, etc. (VIRNO, 2001, p.53).

Eis, portanto, o que vende o trabalhador no momento em que se apresenta no mercado de trabalho para oferecer a própria "mercadoria": na sociedade capitalista, observa Marx, o trabalhador assalariado vende, troca a própria força de trabalho - ou seja, as próprias faculdades produtivas, a própria possibilidade de produzir, a atividade criadora de valor - por um valor predeterminado (um salário)

\footnotetext{
${ }^{15}$ [...] ação é também uma objetivação do pensamento, isto é, representa a solução generalizante, dada pelo sujeito, a um problema relacionado com o objeto. Nesse sentido podemos também afirmar que os instrumentos de trabalho e seus usos são objetivações do pensamento humano como a linguagem. (HELLER, 2012, p.246).
}

TrabalhoNecessario - www.uff.br/trabalhonecessario; Ano 15, № 27/2017 
e, além disso, a troca acontece independentemente do resultado de sua atividade $^{16}$. (MARX, 1968).

Dito isso, a primeira consideração a fazer é que a categoria marxiana de força de trabalho somente hoje atinge sua máxima concretude, assumindo sua real e plena validade nas condições históricas atuais. Efetivamente, até o período fordista, ou seja até 30 anos atrás, o capital utilizava e explorava quase que exclusivamente as capacidades físicas, materiais, basicamente o corpo da força de trabalho. Hoje, entretanto, além das capacidades físicas, são transformadas em valor também as potencialidades intelectuais, mentais, linguísticas e relacionais, isto é, a totalidade das faculdades humanas.

Segundo a teoria econômica do capitalismo cognitivo (CILLARIO, 1996; VERCELLONE, 2006 e 2012), na passagem do fordismo ao pós-fordismo, o trabalho assalariado não mais se caracterizaria pela mera execução de tarefas, e sim pela reflexividade. Ou seja, qualquer trabalhador assalariado (do operário, ao escriturário ou engenheiro informático) teria a incumbência de desenvolver uma função ideativa (direcionada a refletir sobre os diversos procedimentos organizativos a serem utilizados para aumentar a produtividade do trabalho ${ }^{17}$. Em suma, a participação reflexiva do trabalho tem por base a capacidade de elaboração de novos métodos organizativos e esquemas relacionais que permitem ao capital aumentar a produtividade do trabalho. Obviamente a reflexibilidade não é uma livre escolha, e sim imposta coercitivamente pelas empresas. Dessa forma, o capital não explora mais somente a força física do operário, mas também sua capacidade de pensar e formular melhorias na produção, suas capacidades reflexivas e intelectuais.

Ora, ao repensar o conceito de força de trabalho em Marx, nos rendemos conta de que, na realidade, a exploração das capacidades cognitivas dos trabalhadores não significa propriamente algo tão inovador dentro da natureza do processo de valorização do capital ${ }^{18}$. Pelo contrário, o fato de que atualmente,

\footnotetext{
${ }^{16} \mathrm{~A}$ relação capitalista de produção está fundada precisamente sobre a diferença entre o valor de troca da força de trabalho e o trabalho efetivamente realizado.

17 "A maior transformação que, a partir da crise do fordismo, sinaliza o declínio do capitalismo industrial, encontra-se justamente na revalorização da dimensão cognitiva e intelectual do trabalho"(VERCELLONE, 2012).

${ }^{18}$ Procopio escreve o seguinte: "Apresentar a exploração da contribuição intelectual dos operários na produção como uma novidade desta fase particular do capitalismo, é um grande contrassenso que tem servido exclusivamente para considerar a teoria do valor-trabalho superada, sem fornecer, porém, nenhuma demonstração científica a esse tipo de declaração. No regime
} 
além das capacidades físicas, sejam diretamente exigidas dos trabalhadores, e de uma forma substancialmente generalizada, também suas potencialidades intelectuais (linguísticas, cognitivas, relacionais), significa somente a plena efetivação da categoria marxiana de força de trabalho.

De qualquer forma, a passagem da subsunção formal à subsunção real do trabalho ao capital subjugou primeiro a atividade produtiva prática, o trabalho físico, manual (por ser um objeto passível de mensuração relativamente mais simples) e, sucessivamente, o trabalho cognitivo, intelectual, relacional, linguístico. Efetivamente, no pós-fordismo a subsunção real consegue atingir, além do corpo, também a mente da força de trabalho.

Lembremos que, com o termo subsunção formal do trabalho ao capital, Marx entende que o capital submete a si, isto é, à lógica de sua própria reprodução (criação de mais valia e lucro), um modo de trabalhar já desenvolvido pelos seres humanos muito antes do surgimento do capitalismo e independente dele. $O$ que o capital faz é submeter 0 trabalho às suas próprias finalidades apenas formalmente, ou seja, sem mudar o conteúdo da ação laborativa. $\mathrm{O}$ conceito de subsunção real, no entanto, designa a constituição de um processo produtivo especificamente capitalista e se concretiza no momento em que o capital faz emergir.

um modo de produção específico, e não apenas tecnologicamente, que transforma totalmente a natureza real do processo de trabalho $e$ as suas condições reais: o modo capitalista de produção. [...]. Na subordinação real do capital aparecem no processo de trabalho todas as transformações que anteriormente analisáramos. Desenvolvem-se as forças produtivas sociais do trabalho e, graças ao trabalho em larga escala, chegase à aplicação da ciência e da maquinaria à produção imediata. (MARX, 1969, p.68-69). [Ed.bras: MARX, O Capital, Cap.VI Inédito, Ed.Moraes, 1985, p.104-105].

Em todo caso é preciso deixar claro que subsunção formal e subsunção real do trabalho ao capital não são dois momentos de um processo unidirecional e

capitalista o valor de troca das mercadorias é determinado pela quantidade de trabalho socialmente contido, e todas as oscilações desse valor decorrem apenas da variação da quantidade de trabalho despendida. Declarar essa teoria superada apenas porque nos dias atuais o capital consegue explorar também a capacidade reflexiva do trabalho operário é simplesmente uma afirmação que não demonstra absolutamente nada quanto ao suposto fim da teoria do valortrabalho." PROCÓPIO, 1999). 
temporalmente orientado. Na realidade, eles convivem e se entrelaçam em diferentes proporções segundo o contexto histórico, social e cultural.

$\mathrm{Na}$ chamada fase posfordista é possível observar uma extensão e uma intensificação do processo de subordinação real do trabalho ao capital: os trabalhadores passam a ser expropriados não somente de seu próprio trabalho, do próprio saber prático, das ferramentas (que orientam sobretudo a atividade material concreta), mas também dos seus próprios conhecimentos, do próprio saber (que o capital tende a objetivar em ações e conhecimentos formalizados e processados de modo que possam ser quantificados, medidos, objetivados e reificados).

[...] O trabalhador intelectual encontra hoje um saber já formado, cujo conteúdo está dissociado de sua experiência e conhecimentos anteriores. Não pode mais indagar a respeito do processo de construção desse saber [...]. O procedimento matemático que transforma a coisa em pensamento e o pensamento em coisa agora se contrapõe a ele irremediavelmente como um instrumento universal para a construção de conhecimentos; como condição objetiva material da produção; como uma máquina capitalista que tornou obsoleto e não confiável o cérebro humano. A experiência anterior do trabalhador não pode mais, de nenhuma forma, nem guiar, nem controlar os algoritmos ${ }^{19}$ que transcendem seu mundo sensível, vindos "não se sabe de onde, nem de quem, tendo como base princípios dos quais desconhece a origem". Por esse motivo o pensamento reificado condena o trabalho mental à menoridade, ao dogmatismo que não é apenas, como antes, uma afecção do espírito, mas tornou-se condição material à qual não é possível subtrair-se. (MODUGNO, 2010).

A mercantilização da atividade produtiva, de sua capacidade humana produtiva, sofre, portanto, um processo de sucessivo aprofundamento que termina por envolver - além da criação de objetos, instrumentos e produtos - também a produção de símbolos, sentidos e significados, características que, como sublinhamos anteriormente, distinguem o ser humano dos outros animais. ${ }^{20} \mathrm{Com}$

\footnotetext{
${ }^{19}$ Isto é, receitas prontas detalhando minuciosamente os procedimentos necessários para a resolução das tarefas. (N.T.)

${ }^{20}$ Para Marx, no modo de produção capitalista, o trabalhador é uma pessoa desumanizada, que age mecânica e repetitivamente; que é dominado e que deve favorecer a inexorável valorização do capital. A capacidade de resposta ativa e planejada, a criatividade e a flexibilidade, a capacidade de ação própria do animal humano é reduzida e virada de cabeça para baixo, transformada numa "reatividade" passiva e irrefletida. Dessa forma, não só as necessidades humanas se enfraquecem, mas definitivamente também aquelas que temos em comum com os outros animais (MARX, 2004): alienação / estranhamento significa, assim, desumanização. Em
} 
efeito, é possível argumentar como Heller, que a linguagem faz plenamente parte do conjunto da atividade produtiva do ser humano. ${ }^{21}$

A linguagem também faz parte do trabalho: nem mesmo o trabalho mais primitivo pode ser efetuado sem informações linguísticas, comandos, sem os vários tipos de comunicação linguística. É bem conhecida a história bíblica, segundo a qual, a torre de Babel não pode ser concluída porque Deus confundiu a linguagem dos construtores. Sem a mediação linguística 0 trabalho não podia ser desenvolvido [...]. Além disso, uma das funções da linguagem consiste em orientar a utilização dos meios (instrumentos, objetos) no plano mental, facilitando o exercício de seu emprego. (HELLER, 2012, p.243-244).

Marx observa que o processo de produção assume uma forma tanto mais adequada ao capital quanto mais o trabalho perde suas características particulares, artesanais; quanto mais ele assume a forma de uma atividade genérica, indiferente a cada forma particular. Em poucas palavras, quanto mais o trabalhador se torna alienado em relação ao conteúdo do próprio trabalho:

Portanto, o desenvolvimento pleno do capital só acontece - ou o capital só terá posto o modo de produção que lhe corresponde quando o meio de trabalho é determinado como capital fixo não só formalmente, mas quando tiver sido abolido em sua forma imediata, e o capital fixo se defrontar com o trabalho como máquina no interior do processo de produção; quando o processo de produção em seu conjunto, entretanto, não aparece como processo subsumido à habilidade imediata do trabalhador, mas como aplicação tecnológica da ciência. Por isso, a tendência do capital é conferir à produção um caráter científico, e o trabalho direto é rebaixado a um simples momento desse processo. (MARX, 1968 II, p.393) [Ed.bras: MARX, 2011. Elementos fundamentais para a crítica da economia política (Grundrisse). São Paulo : Boitempo ; Rio de Janeiro : Ed. UFRJ, 2011, p. 933].

A crescente aplicação tecnológica da ciência (como produto do desenvolvimento social e da produtividade em geral) ao processo de produção imediato constitui precisamente um dos aspectos mais relevantes da subsunção real do trabalho ao capital. O próprio desenvolvimento científico, isto é, as forças produtivas gerais do cérebro social apresentam-se, em relação ao trabalho,

outras palavras significa que a essência humana (o que caracteriza o ser humano enquanto espécie e o distingue em relação aos outros animais) é afetada e colocada em perigo, exposta ao risco de ser violentamente negada e irremediavelmente perdida.

21 A linguagem guia o pensamento nas outras formas de objetivação da atividade humana. Diferentemente dos animais, no homem o desenvolvimento das habilidades manuais e da linguagem ocorrem simultaneamente, tanto é que a linguagem torna-se o princípio guia também de todas as atividades manuais. 
absorvido e incorporado diretamente no capital. ${ }^{22}$ Assim como o desenvolvimento da ciência social, da produtividade da sociedade e o progresso geral apresentamse como desenvolvimento do capital e, enquanto tais, se contrapõem materialmente ao trabalho, como ciência alheia, como capital: "[...] a produtividade do capital se desenvolve com este progresso geral que o capital gratuitamente se apropria". (MARX, 1968 II, p.393).

Atualmente, mesmo no caso dos chamados trabalhadores do conhecimento

[...] as 'máquinas informáticas' desempenham a mesma função das máquinas da grande fábrica: são um instrumento que a empresa utiliza para a produção de valor. Efetivamente, os trabalhadores da economia do conhecimento correspondem apenas em mínima parte àquela imagem de 'super técnicos' criativos, aptos à produção contínua de novas ideias que frequentemente Ihes é atribuída. $\mathrm{Na}$ realidade atuam principalmente como apêndices das novas máquinas informáticas, e executam um trabalho repetitivo e regulado por normas precisas. (CODELUPPI, 208, P.27).

Portanto, o próprio fato de que o conhecimento, no posfordismo, tenha se tornado a principal fonte de produção da riqueza, não seria absolutamente uma novidade:

Acredito que meus amigos do capitalismo cognitivo se enganem ao considerar o 'conhecimento' como a fonte da valorização e exploração. Não é uma novidade o fato de que a ciência, a habilidade, as inovações tecnológicas e organizativas representem as forças produtivas - Marx já o havia afirmado na metade do século XIX; mas a alegada economia do conhecimento não representa a totalidade das relações de classe que a teoria do capitalismo cognitivo Ihe atribui. Esta não é mais do que um dispositivo, um tipo de atividade, uma articulação das relações de poder que dá suporte a uma multiplicidade de outras atividades e outras relações de poder, sobre as quais não exerce nenhuma hegemonia. (LAZZARATO, 2012, p.65).

A própria revolução digital, escreve Formenti (2011), como todas as revoluções tecnológicas, de um lado permitiria ao capitalismo submeter atividades antes não situadas sob o domínio da mercantilização. Por outro lado, favoreceria inclusive o nascimento de novos espaços de autonomia social, embora destinados em seguida a serem absorvidos no processo de valorização do capital. Basicamente, o autor sustenta que os novos mecanismos de produção de valor que se fizeram presentes com a new economy levaram a um substancial

\footnotetext{
${ }^{22}$ E sua aplicação como ciência no processo de produção imediato apresenta-se separada, distinta da capacidade e do saber do trabalhador individual.
}

TrabalhoNecessario - www.uff.br/trabalhonecessario; Ano 15, № 27/2017 
processo de taylorização do trabalho cognitivo (um taylorismo digital direcionado a submeter o trabalho vivo ao domínio das máquinas, software e algoritmos), a um tipo de regressão do trabalho de ideação, criativo, rechaçando as visões utópicas dos anos 1990 em relação à construção de uma classe criativa e às perspectivas de libertação abertas pela web.

Ao contrário, as tecnologias eletrônico-informáticas, mais que favorecer a libertação da atividade produtiva do domínio do capital, constituiriam a base para excepcionais incrementos de produtividade, particularmente no trabalho "criativo" (em relação ao qual, os softwares, freando a dinâmica de alteração da demanda de trabalho intelectual em direção a atividades mais elevadas, tenderiam a substituir e tornar obsoleto o trabalho humano nas atividades de planejamento, gestão e controle).

Em síntese, é possível afirmar que, na fase atual, através das tecnologias digitais é possível determinar um novo desenvolvimento no processo de subsunção real do trabalho ao capital. Hoje o verdadeiro agente do processo laborativo global não é absolutamente representado pelo trabalhador individual, e sim por uma força de trabalho cada vez mais articulada socialmente, de forma que os próprios trabalhadores do conhecimento, os trabalhadores intelectuais, estão hoje já englobados no interior do trabalhador produtivo global, nas diversas forças de trabalho cooperantes que estruturam a totalidade da máquina produtiva, portanto, diretamente explorados pelo capital e submetidos ao seu processo de produção e valorização.

\section{A subsunção real do trabalho cognitivo-relacional: o caso dos operadores do call center}

Ocupemo-nos agora em compreender como ocorre o processo de subsunção real do trabalho no interior de um processo produtivo que nos últimos anos tem registrado uma considerável dinamicidade ocupacional: o call center, ou melhor, os contact center. ${ }^{23}$

\footnotetext{
${ }^{23}$ Nos anos 1990 os call centers se transformaram progressivamente em contact center: o contact center acrescenta à utilização do telefone novos meios tecnológicos de comunicação, tais como fax, e-mail, sms e web, oferecendo assim novos serviços que ultrapassam os "limites do fone de ouvido" e constituem um verdadeiro e próprio centro de contato [relacionamento] entre a empresa e o mundo exterior.
} 
Alguns autores (BUTERA, DONATI e CESARIA, 1997; RULLANI, 2004르 e 2004b) concentram-se principalmente naqueles aspectos inovadores dos call centers, os quais, segundo esta interpretação deveriam ser considerados como verdadeiras "organizações do conhecimento" (knowledge-based organization) ${ }^{24}$. Isto porque os operadores, desenvolvendo um trabalho de natureza sobretudo comunicativa, exerceriam complexas atividades baseadas em conhecimentos relativamente amplos, e estão inseridos no interior de um processo de aprendizagem contínua (contribuindo, por sua vez, a gerar novos conhecimentos). Em contraposição, outros estudiosos (SOPRANI e CREA, 2005) tendem a equiparar o trabalho nos call centers aos tradicionais métodos organizativos e gerenciais da fábrica teylorista-fordista: flexibilidade de horários, ritmo de trabalho extremamente intenso, tarefas excessivamente parcelizadas e monótonas. De modo que

[...] até mesmo nos casos em que, aparentemente, o trabalho dos operadores segue um modelo do tipo "problem solving" (resolução de problemas), suas atribuições, e, portanto, as competências exigidas são relativamente modestas [...]. De fato fica evidente que o método "problem solving" fica limitado ao fato de que os operadores, na maior parte dos casos, encontram a solução dos problemas dos clientes através de uma simples consulta aos softwares disponibilizados pelas empresas. Os softwares são periodicamente atualizados de acordo com as perguntas mais frequentes colocadas pelos mesmos funcionários operadores que atendem os telefonemas dos clientes. (IRES, 2002, p.25).

No que concerne à nossa análise, em primeiro lugar é possível concordar com a interpretação segundo a qual a principal capacidade explorada nos call centers é a capacidade linguística, comunicativa, cognitivo-relacional dos trabalhadores. Efetivamente os operadores do tele atendimento devem possuir uma adequada bagagem formativa, o que significa, em poucas palavras, que devem possuir um certo grau de estudo, enquanto as capacidades linguísticas e relacionais se desenvolvem através da experiência (que se adquire no âmbito laborativo, mas, sobretudo, extra laborativo) e do processo educativo. Trata-se, todavia, de habilidades medianas, comuns, genéricas, aprendidas "naturalmente",

\footnotetext{
${ }^{24}$ BUTERA F.; DONATI E.; CESARIA R. 1997. Os trabalhadores do Conhecimento. Ed. FAngeli, 1997.
} 
vivendo e crescendo no interior do próprio contexto social ao qual pertence, e do qual, qualquer ser humano em geral está em condições de apropriar-se.

As empresas explorariam algumas competências básicas normalmente associadas à aquisição de um diploma de Ensino Médio (segundo ciclo ${ }^{25}$ ), com aperfeiçoamento nas áreas de linguística e informática), e algumas habilidades típicas da força de trabalho jovem (habilidade relacional e comunicativa) para atividades de comunicação com os clientes/usuários que requerem uma formação ágil, direcionada principalmente ao trabalho e que não requer investimentos na estabilidade da força de trabalho. (AVOLA e PALIDDA, 2013, p.2).

Do ponto de vista das características gerais do trabalho desenvolvido pelos operadores, é possível evidenciar que: 1) aos trabalhadores é exigida uma grande disponibilidade uma vez que as operações de tele atendimento ocorrem em ciclo contínuo, ou seja, são realizadas no decorrer das 24 horas diárias e nos sete dias da semana; 2) a atividade dos operadores é totalmente submissa à pressão do fluxo informático ${ }^{26}$ - ao término de uma chamada segue-se imediatamente uma outra, seja de forma automática (a intervalos de 0 a 20 segundos, conforme o tipo de operação), seja manualmente, depois de, no máximo, dois ou três toques; 3) a atividade dos trabalhadores é guiada pela rotinização da comunicação ${ }^{27}$, subordinada a rígidos scripts ${ }^{28} \mathrm{e}$ aos modelos de execução formatados pelos softwares, além de estritamente controlados pelos supervisores: a vigilância constante e capilar de tudo o que acontece no interior do local de trabalho desempenha um papel preciso, duradouro e funcional ao "bom adestramento". 29

\footnotetext{
${ }^{25}$ O Ensino Médio na Itália é constituído por 2 clicos: I ciclo = Scuola Media (de 11 a 13/14 anos, duração 3 anos). Ensino Médio- II ciclo = Scuola Media Superiore ( de 14 anos a 18/19 anos, duração 5 anos) (N.Trad.).

${ }^{26}$ Os softwares utilizados giram automaticamente as chamadas ao trabalhador livre mais próximo, de modo que os trabalhadores são submetidos passivamente à programação do trabalho.

${ }^{27}$ Como declarado por quem se ocupa da formação dos operadores, o controle da própria atividade, o saber fazer bem o próprio trabalho se adquire com a prática e, portanto, com a repetição (Massei Luca, responsável pela formação dos operadores no Data Center).

${ }^{28}$ Esquemas de gestão das ligações.

${ }^{29}$ No que se refere à rotinização da comunicação e ao adestramento dos operadores, veja-se, por exemplo, o papel desenvolvido pelos simuladores de call center, os quais são direcionados a treinar os operadores de contact center a maximizar a capacidade de "concluir" a ação (seja tratando-se de venda ou assistência) através da "compreensão" do cliente e de suas necessidades expressas e latentes: "O simulador contém todas as técnicas de negociação típicas [...] para colocar à prova o operador em cada fase [...]. O simulador prevê a interação com quatro diferentes sujeitos, cada um delineado com base num perfil sociocultural, numa necessidade primária e a um latente e específico perfil psicológico. Para treinar não só a técnica mas também a capacidade de
} 
As formas e as técnicas através das quais se realiza o controle são complexas e diversificadas: desde a supervisão hierárquica direta ao monitoramento eletrônico em tempo real (amplamente utilizado tanto para intensificar a produtividade, quanto para controlar os padrões de qualidade das conversas telefônicas), até à pressão do próprio grupo de trabalhadores (que se expressa através do trabalho em equipe).

Como observa Braga:

Em última instância, trata-se de um tipo de trabalho que testemunha como nenhum outro a taylorização do trabalho intelectual e do campo da relação de serviço: uma comunicação instrumental sob a coerção do fluxo informacional e prisioneira do script, tendente a transformar o tele operador numa espécie de autômato inquieto. Os objetivos são claros: multiplicar as operações e diminuir seus custos por meio da redução do estatuto da comunicação à condição de pura instrumentalidade. (BRAGA, 2007).

Embora existam diferenças até importantes, entre as diversas tipologias de call centers, o trabalho dos operadores é, em geral, uma atividade de rotina e submetida aos rígidos cânones do taylorismo (semelhante ao operário de linha de montagem de uma fábrica automobilística, um operador de tele atendimento é facilmente substituível), ao qual se acrescem novas modalidades de exploração e controle do trabalho típicas da lean production (produção enxuta): trabalho em equipe, participação ativa dos trabalhadores no processo produtivo, etc.

Concluindo, as tecnologias eletrônico-informáticas e os softwares utilizados no interior dos contact centers servem para subsumir, controlar e mensurar o trabalho cognitivo-relacional dos operadores. De modo que a subsunção real do trabalho intelectual ao capital, neste caso, se efetiva através dos vários softwares, scripts, da adequação e constante pressão do fluxo informático. Em poucas palavras, a expropriação do saber profissional e dos conhecimentos práticos do operador se concretiza através da criação de softwares e de procedimentos (implementados por meio da tecnologia e da ciência aplicadas à produção) que

adequar a própria forma de abordagem ao contexto específico." Na prática, trata-se de um treinamento intensivo a respeito das técnicas de comunicação que devem permitir ao operador otimizar "sem riscos" a própria abordagem ao cliente. O objetivo final desse adestramento é, evidentemente, o de tornar "natural", "instintivo", espontâneo e mecânico o comportamento comunicativo instrumental imposto. 
eliminam gradualmente o conteúdo comunicativo compreensível que caracteriza a relação de serviço. Desta forma, os conhecimentos se objetivam, se reificam, se autonomizam, se separam do trabalhador, contrapondo-se a ele como saber estranhado, como produto e meio de produção do capital: o produto do trabalho intelectual não é mais inseparável do produtor e do ato de produzir.

\section{REFERÊNCIAS}

AVOLA M.; PALIDDA R. (2013). Lavorare in un call center in una città del Sud. StrumentiRes, - Rivista online della Fondazione Res. Anno V, n.4. Disponível em http://www.strumentires.com/attachments/article/498/Lavorare_in_Call_Center_Av ola_Palidda_.pdf

BERTHOUD, G. (1994). II mercato come simulacro del dono. In AA.VV., I/ dono perduto e ritrovato, Manifestolibri, Roma.

BRAGA, R. (2007). "Un'altra faccia" del lavoro informazionale e immateriale. La vendeta di Braverman. Proteo, Roma, n.3.

BRUNER, J.(2001). La cultura dell'educazione, Ed.Feltrinelli, Milano.

BUTERA F.; DONATI E.; CESARIA R. (1997). I lavoratori della Conoscenza. Ed.Franco Angel, Milano.

CILLARIO L. (1996). L'economia degli spettri. Forme del capitalismo contemporaneo. Ed.Mondadori, Milano.

CIMATTI, F. (2000). La scimmia che si parla. Ed.Bollati Boringhieri. Torino.

Editori Riuniti, Roma.

(2002). La mente silenziosa. Come pensano gli animali non umani.

CODELUPPI, V. (2008). II biocapitalismo. Verso lo sfruttamento integrale di corpi, cervelli ed emozioni. Ed.Bollati Boringhieri. Torino.

FOMENTI, C. (2011). Felici e sfruttati. Capitalismo digitale ed eclissi del lavoro. Ed.Egea, Milano. 
GALIMBERTI, U. (2008). Psiche e techne. L'uomo nell'età della tecnica. Ed.Feltrinelli, Milano.

GEHLEN, A. (1990). L'uomo. La sua natura e il suo posto nel mondo. Ed.Feltrinelli, Milano.

HELLER, A. (1977). La teoria dei bisogni in Marx. Ed. Feltrinelli, Milano. . (2012). Sociologia della vita quotidiana. Pgreco Edizioni, Milano.

IRES (2002). I call centers in Europa. Progetto Tosca, Social Observation Table of Call Centers.

LEROI-GOURHAN, A. (1977). II gesto e la parola. I. Tecnica e linguaggio. Ed.Einaudi, Torino.

MARX, K. (1968). Lineamenti fondamentali della critica dell'economia politica. Ed. La Nuova Italia, Firenze.

Firenze. . (1969). I/ Capitale. Libro 1, capitolo VI inedito. Ed. La Nuova Italia, . (1977). Lavoro salariato e capitale. Editori Riuniti, Roma. . (2004). Manoscritti economico-filosofici del 1844. Ed. Einaudi, Torino.

MODUGNO, E. (2010). Alla scoperta del Moro. Il manifesto, 15 luglio. Cittá... Ed.

PETRACCHI, G. (1995). Decondizionamento. Ed.La Scuola, Brescia.

PEZZANO, G. (2012). Ripensare (con) Marx: la natura umana tra filosofia, scienza e capitale. Ed. Petite Plaisance, Pistoia.

PROCOPIO, L. (1999). Il capitalismo cognitivo e il neo riformismo. Prometeo n.18. V serie. Cittá... Ed...

RULLANI, E. (2004a). La fabbrica dell'immateriale. Produrre valore con la conoscenza. Ed.Carocci, Roma. 
(2004b). Economia della conoscenza. Creatività e valore nel capitalismo delle reti. Ed.Carocci, Roma.

SOPRANI, S; CREA, P. (2005). Power and Labour Process in Contemporary Taylorism: Workers' Visibility and Invisibility in Call Centers. Fibre Culture, n.5. Cittá, Ed...

VERCELLONE, C. (2006). Capitalismo Cognitivo. Ed. Manifestolibri, Roma. . La legge del valore nel passaggio dal capitalismo indusriale al nuovo capitalismo. UniNomade, 27/08/2012 (http://uninomade.org/vercellonelegge-valore/).

VIRNO, P. (2001). Grammatica della moltitudine. Ed.Rubbetino, Soveria Mannelli.

VYGOTSKIJ, L.S. (1987). Il processo cognitivo. Ed. Bollati Boringhieri, Torino.

Recebido em: 02 de abril de 2017 Aprovado em: 05 de outubro de 2017 Publicado em: 5 de dezembro de 2017 